\title{
Asymmetric fuel price responses under heterogeneity
}

Jacint Balaguer and Jordi Ripollés

Department of Economics, Jaume I University of Castellon, Spain (e-mails: jacint.balaguer@uji.es; jripolle@uji.es)

\begin{abstract}
We explore the effect of cross-sectional aggregation of data on estimation and test of asymmetric retail fuel price responses to wholesale price shocks. The analysis is performed on data collected daily from individual fuel stations in the Spanish metropolitan areas of Madrid and Barcelona. Our findings suggest that the typical estimation with aggregated data clearly tends to overestimate the persistence of shocks. Moreover, we show that aggregation may generate a loss of efficiency in econometric estimates that is sufficiently large to hide the existence of the "rockets and feathers" phenomenon.
\end{abstract}

Keywords: Fuel pricing behavior, asymmetry, daily data, cross-sectional aggregation. JEL classification: C31, C32, C33, D43, Q40 


\section{Introduction}

Since Bacon's (1991) seminal paper, an increasing number of empirical studies have explored the adjustment of fuel prices in response to their input price shocks. Scholars have paid special attention to check whether, as consequence of a high level of efficiency, the adjustment process is rapid and symmetric. An overview of the literature reveals that the existing results are rather mixed even for an analysis of the same context, unfortunately making it difficult to reach any firm conclusions on this question (e.g., Perdiguero-García, 2013). Some authors (e.g., Bachmeier and Griffin, 2003; Bettendorf et al., 2003), have shown that the diversity of results may be explained to some extent by temporal aggregation of data at a weekly or monthly level, since in this case the highest frequency of response to shocks is ignored. That is, temporal aggregation may cause omission of a set of distributed lag variables regardless of the functional form of the dynamic model applied which, in turn, would generate serious estimation bias as defined by Geweke (1978). Since this econometric limitation has been recognized, interest in collecting and using daily fuel prices has increased in an attempt to obtain more accurate evidence on the issue (e.g., Al-Gudhea et al., 2007; Bettendorf et al., 2009; Balaguer and Ripollés, 2012; Kuper, 2012; Wlazlowski, et al., 2012; Valadkhani, 2013). However, even when daily data are used, some limitation could arise in the analyses of fuel retail price responses for regions or countries, since most of them continue in the tradition of using aggregated data across fuel stations. Hence, their conclusions are implicitly based on the "representative agent" assumption, which may not be well suited. At this stage of the research it seems appropriate to ask how measuring fuel price responses might be further improved by adopting a supplementary empirical strategy consisting of disaggregating daily data in a crosssectional dimension and, therefore, relaxing this standard assumption. The theoretical econometric background, results on price transmission for non-fuel products, and the estimated persistence of induced adjustments in many of the fuel markets analyzed, are three aspects that encourage us to explore this question.

The possible gain in estimates derived from cross-sectional disaggregation of data has been widely discussed since the early contribution of Theil (1954). To date, numerous papers have studied this subject for dynamic models. There is broad consensus that the dynamics exhibited by time series for heterogeneous individuals may be markedly different from those displayed by a time series derived from the aggregation of the data, 
therefore compromising the validity of estimations when the latter time series are used (e.g., Granger, 1980; Trivedi, 1985; Stoker, 1993; Pesaran and Smith, 1995; Pesaran, 2003). For our purposes, special attention should be given to the particular outcome provided by Lippi (1988) for error correction models, since they have been extensively applied in analysis of fuel price responses. It has been shown that, under these models, there is cross-sectional aggregation bias that clearly tends to overstate the dynamic process on its way toward the equilibrium. In this regard, it seems reasonable to apply regressions for micro units which allow us to capture any adjustment specificities to provide a more realistic view. In line with the idea underlying some modern panel data procedures such as those developed in Pesaran and Smith (1995) and Pesaran (2006), an overview of the market behavior can then also be obtained by averaging the specific estimated coefficients.

There is currently some evidence of vertical price transmission for non-fuel oil products which are consistent with the theoretical predictions discussed above. For example, Powers (1995) and Peltzman (2000) showed that estimations with cross-sectional aggregated data for several supermarket products reveal an artificial slowing down of the estimated wholesale-retail price responses. Similar results were obtained in CramonTaubadel et al. (2006) for an analysis of German food products. This sort of aggregation bias has also been demonstrated in international price transmission. More specifically, Imbs et al. (2005), Broda and Weinstein (2008), and Roberston et al. (2009) found that when heterogeneity of traded products is not taken into account, the estimated dynamics are overstated and the increase in the persistence of shocks of real exchange rates is exaggerated.

Lastly, another motivation for our research question comes from existing estimates on fuel price responses in the latter part of the distribution chain. In a review of the literature, many studies found that the estimated dynamic process following an isolated oil shock is suspiciously slow and persistent over time until the price level equilibrium is reached. Indeed, as can be seen from the selected papers in Table 1, the overall adjustment in the studied markets does not often close $50 \%$ of the gap even after an estimated period of several weeks, regardless of the geographical context, data frequency, and econometric methodology chosen. Nevertheless, considering that fuel 
stations in the investigated markets are completely free to adjust their prices daily after frequent oil price shocks, these empirical results seem rather surprising. ${ }^{1}$

\section{[Please insert Table 1 here]}

The present paper uses panel data resulting from statistical information collected daily for a large set of fuel stations. ${ }^{2}$ Specifically, we focus on data from the metropolitan areas of Madrid and Barcelona, which have a substantial number of Spanish fuel stations. This allows us to explore, on the one hand, the advantages of cross-sectional data disaggregation to improve knowledge of fuel price responses and test their hypothetical asymmetries. On the other hand, we provide new evidence on a context for which the empirical results are somewhat puzzling to date, since the adjustment toward equilibrium takes a large number of days and there is no consensus about whether asymmetries have occurred, even in similar studied periods (e.g., Galeotti et al., 2003; Contin-Pilart, et al. 2009).

We adopt the mean group (MG) approach of Pesaran and Smith (1995) which combines at least three possible advantages of the traditional estimates from OLS with crosssectional aggregated data. First, it allows us to control for unobserved heterogeneity across fuel stations (both differences in markups as well as in dynamic behavior). Second, it also makes it possible to further incorporate common correlated effects (MGCCE), as proposed by Pesaran (2006). Specifically, in line with the recent paper by Eberhardt and Teal (2012), we implement the MG-CCE by taking into account possible cross-sectional dependence with the nearest neighboring fuel stations. Thus, for example, it will allow us to consider that fuel stations located in high traffic intensity zones on certain days may be taking advantage of the large volume of demand during this period together with their neighboring stations. Third, since cross-sectional disaggregation for both metropolitan areas will provide a large amount of statistical information, we obtain more degrees of freedom and more sample variability. We therefore expect that the power of test for asymmetries will be considerably increased.

\footnotetext{
${ }^{1}$ These outcomes contrast with those obtained by Bettendorf et al. (2009), who analyzed the daily retail price adjustments to wholesale shocks for a single firm. Particularly, the authors found that the half-life of Shell's price transmission in the Netherlands is reduced to about five days. This result reinforces our suspicion that many of the existing estimations concerning pricing behavior in retail fuel markets fail to give us an accurate overview of the real pricing dynamics of firms that operate in those markets.

${ }^{2}$ To our knowledge, the paper by Noel (2009) is the only one that uses daily prices for a set of individual fuel stations in order to study dynamic pricing behavior. However, unlike our work, the aim of this author is to examine Edgeworth Cycles.
} 
The rest of the paper is structured as follows. In Section 2 we present the sources and some characteristics of our dataset, perform a time series analysis, and detail the empirical specification and methodologies. Section 3 provides the main results from the micro units and aggregated data, and discusses the differences among them. Concluding remarks are presented in Section 4.

\section{Empirical framework}

\subsection{Data}

We analyze fuel stations located in Spain's two largest metropolitan areas: Madrid and Barcelona. Because there is no a single official definition of the Spanish metropolitan areas, we considered different proposals. For the metropolitan area of Madrid we adopt the definition provided by García Ballesteros and Sanz Berzal (2002). In the case of Barcelona we follow the territorial division proposed by the General Territorial Plan of Catalonia in accordance with autonomous law 1/1995 (published in the Official Journal of the Generalitat of Catalonia 2032).

For each one of these geographical areas we collected daily information on the retail prices (Euros/liter) for diesel fuel. ${ }^{3}$ These data were taken from the website of the Spanish Ministry of Industry, Energy and Tourism (http://geoportal.mityc.es/). Because the current prices only remain on this website for the day in question and under Spanish law (Order ITC/2308/2007) historical data cannot be published, ${ }^{4}$ all retail prices were extracted daily throughout the period from June 10, 2010, to November 25, 2012. It should be noted that some fuel stations did not provide price-setting information for some of the days on which we collected the data (for reasons such as repair work or vacation closure). As result we study the pricing dynamics on a final sample of 900days, which corresponds to 283 and 185 fuel stations located in the areas of Madrid and Barcelona, respectively. The empirical study therefore includes, for any day of the period considered, the retail prices set by more than $60 \%$ of the total population of fuel

\footnotetext{
${ }^{3}$ Diesel fuel represents about $80 \%$ of total fuels used in Spain for road transport (according to annual data for 2012 from the Asociación Española de Operadores de Productos Petrolíferos).

${ }^{4}$ Fuel stations are required to submit current retail prices to the Ministry every Monday and whenever changes are applied. Information on changes in retail prices is generally submitted several days per week.
} 
stations in each of the two areas. All retail prices are expressed net of taxes following the information published by the Spanish Ministry of Economy's Tax Office. ${ }^{5}$

The wholesale prices of the corresponding raw material are the Amsterdam-RotterdamAntwerp market spot prices (Euros/liter), taken from the Platts database (code AAQCI00). Missing values resulting from closure of the spot market on weekends and vacations were completed with prices from the previous day.

Lastly, the geographical location of each fuel station in both areas was also collected from the Ministry of Industry, Energy and Tourism website with the purpose of considering the price of neighboring fuel stations in a part of our empirical analysis. To do so, we take into account the locations of all the fuel stations that open every day, including those that were closed in any part of the period considered. By employing the longitude and latitude information for each selling point, the distance between each of them and their neighboring fuel stations is obtained through the "geosphere" package available in the $\mathrm{R}$ software.

We were interested in discovering the degree of integration of our price series. The empirical strategy that we use for retail prices differs from that adopted for wholesale prices. The reason for this is that Breusch and Pagan's (1980) LM statistic indicates that retail prices are cross-sectionally dependent (with p-values virtually equal to zero). We therefore chose to apply the Breitung and Das (2005) panel unit root test for retail prices ${ }^{6}$ which is robust to the presence of cross-sectional dependence. For wholesale prices we apply the unit root test proposed by Phillips-Perron (1988). Additionally, we were interested in finding the degree of integration of retail prices when they are aggregated at a cross-sectional level. Once more, the Phillips-Perron approach is used for these series. As can be seen in Table 2, variables are non-stationary in levels in all cases, but after taking first differences the null hypothesis of non-stationarity can be clearly rejected.

[Please insert Table 2 here]

\footnotetext{
${ }^{5}$ Specifically, the special tax on hydrocarbons, the general tax established by the State, the taxes applied by the corresponding region (i.e., Autonomous Community), and value added tax (VAT) have all been removed.

${ }^{6}$ This test is particularly suitable for contexts where the number of temporal observations is greater than the number of observations for individuals.
} 
We also examine whether there is a stable long-term relationship among our time series. We chose Westerlund's (2007) bootstrap test to check for cointegration between disaggregated retail prices and wholesale prices. This approach allows for a large degree of heterogeneity and is robust to very general forms of cross-sectional interdependency. The first two statistics for cointegration presented in Table 2 are group-mean tests $\left(G_{\tau}\right.$ and $G_{\alpha}$ ), under the alternative hypothesis that at least one cross-sectional unit is cointegrated. The following statistics are panel tests $\left(\mathrm{P}_{\tau}\right.$ and $\left.\mathrm{P}_{\alpha}\right)$ with the alternative hypothesis that the whole panel is cointegrated. The set of p-values suggests that disaggregated retail prices and wholesale prices are cointegrated for both metropolitan areas. Finally, the Phillips-Perron test provides evidence of cointegration between aggregated retail prices and wholesale prices.

\subsection{The baseline specification}

Because retail and wholesale fuel price series are integrated of order one and cointegrated with each other, the relationship between the two variables can be specified as an error correction model (Engle and Granger, 1987). In line with the typical empirical model, we assume that retail price variations depend asymmetrically on positive and negative changes in the corresponding raw material prices. Unlike most of the studies on this issue, we introduce possible heterogeneity of price-setting behavior for each of the operating firms $(i=1,2, \ldots, N)$ :

$$
\begin{array}{r}
\Delta p_{i t}=\theta_{i}\left(p_{i t-1}-\alpha_{i}-\gamma_{i} t-\sum_{q=1}^{6} \vartheta_{i q} \operatorname{Day}_{q}-\phi_{i} w p_{t-1}\right)+\sum_{m=1}^{M+} \beta_{i m}^{+} \Delta p_{i t-m}^{+} \\
+\sum_{m=1}^{M-} \beta_{i m}^{-} \Delta p_{i t-m}^{-}+\sum_{n=0}^{N+} \delta_{i n}^{+} \Delta w p_{t-n}^{+}+\sum_{n=0}^{N-} \delta_{i n}^{-} \Delta w p_{t-n}^{-}+\varepsilon_{i t}
\end{array}
$$

where $\Delta$ is the first-differences operator, $p_{i t}$ is the retail price of the $i$-th firm at time $t$ $(t=1,2, \ldots, T)$ and $w p_{t}$ represents the corresponding wholesale price at time $t$, which is common for all operating firms. The long-term relationship in the model $\left(p_{i t-1}-\alpha_{i}-\right.$ $\left.\gamma_{i} t-\sum_{q=1}^{6} \vartheta_{i q} D a y_{q}-\phi_{i} w p_{t-1}\right)$ is the error correction. It includes an intercept $\left(\alpha_{i}\right)$, a time trend $(t)$ and a set of daily dummies $\left(D a y_{q}\right)$ to control for the effect on retail prices of possible changes in demand associated with each day of the week. The coefficient of lagged wholesale prices $\left(\phi_{i}\right)$ can be interpreted as the cost pass-through to retail prices for $i$-th firm. The regression coefficient $\theta_{i}$ associated to the error correction term 
represents the speed convergence toward the long-run equilibrium. The superscripts + and - indicate positive and negative variations in prices. Therefore, price changes are $\Delta p_{i t-m}^{+}$and $\Delta w p_{t-n}^{+}$if their respective differences are above zero, and $\Delta p_{i t-m}^{-}$and $\Delta w p_{t-n}^{-}$otherwise. Hence, the short-run dynamics are captured by $\beta_{i m}^{+}$and the $\delta_{i n}^{+}$ coefficients for price rises, and by $\beta_{i m}^{-}$and the $\delta_{i n}^{-}$for price reductions. Finally, $\varepsilon_{i t}$ is a random disturbance term, which is assumed to be iid.

Our operational definition of asymmetries will be based on the resulting cumulative response functions (CRFs) in accordance with the coefficients in Equation (1). ${ }^{7}$ After a shock derived from wholesale price changes in a period $t$, these functions will describe the cumulative retail price adjustment in each period $t+s$ until the level of passthrough $\left(\phi_{i}\right)$ is reached. Thus, presence of asymmetries will be supported when the CRF to positive shocks differs statistically from the CRF to negative shocks.

\subsection{Empirical methodologies}

By using the collected prices for micro units from the two metropolitan areas, we estimate the baseline error correction model represented by Equation (1) through two related panel methodologies. First, we follow the MG approach of Pesaran and Smith (1995). ${ }^{8}$ Unlike conventional panel estimators, we further recognize that parameters can be heterogeneous across individuals. We thereby avoid a potential source of estimation bias that, as these authors point out, would remain even for large time and crosssectional samples. The MG estimator consists of estimating the error correction model separately for each firm. Because the slope coefficients can be heterogeneous, a simple arithmetic average of these coefficients will provide information about the general behavior of firms that operate in the market. Second, as well as considering heterogeneity coming from individual effects and price responses, we also introduce the possibility of spatial dependence. That is, pricing behavior of each $i$-firm can be driven by unobserved factors that are common to their neighboring firms. For this purpose we apply the MG-CCE estimator developed by Pesaran (2006) in a variant recently proposed by Eberhardt and Teal (2012). In practice this econometric extension involves augmenting each MG regression with the lagged cross-sectional average of the retail

\footnotetext{
${ }^{7}$ For a description of how the CRFs are obtained from an error correction specification, see Borenstein et al. (1997).

${ }^{8}$ In Pesaran et al. (1999) we can see an early application of the MG approach under an error correction model.
} 
prices corresponding to neighboring firms. The relative advantage of the MG-CCE estimator is that it gives consistent estimates under a variety of forms of cross-sectional dependence (Pesaran and Tosetti, 2011).

Lastly, we work with aggregated retail prices at a cross-sectional level in order to compare with the estimations discussed above. Under this framework there is clearly no possibility of considering firms' heterogeneity behavior and, in terms of Equation (1),

the subscript $i$ is removed and $p_{i t}$ is replaced by $\bar{p}_{. t}=\frac{1}{N} \sum_{i=1}^{N} p_{i t}$. This restricted model is estimated with the OLS procedure, following the standard approach in the empirical work on the subject.

\section{Results}

\subsection{From disaggregated data}

Table 3 presents the results corresponding to an overview of behavior of firms operating in the metropolitan areas of Madrid and Barcelona, derived from disaggregated retail prices. The number of lags for Eq. (1) is selected on the basis of the Akaike information criterion (AIC), ensuring that the residuals are free of autocorrelation in accordance with Wooldridge's (2002) approach.

[Please insert Table 3 here]

We first report estimates based on the MG approach. Then, we ask ourselves whether the fuel stations' pricing response is critically idiosyncratic, which is an essential question in this study. For this purpose we test the null hypothesis of parameter homogeneity using Swamy's test. Pricing behavior is heterogeneous regardless of the metropolitan area considered according to the results statistics (which are 39,717.21 and 29,081.01 for Madrid and Barcelona respectively, with p-vales virtually equal to zero). This supports the convenience of applying mean group approaches rather than conventional panel estimators with homogeneous parameters across individuals. Moreover, we find the presence of dependence across fuel stations' pricing strategy in view of results for the Bresuch-Pagan LM test (which are 7,537,491 and 6,415,385 for Madrid and Barcelona respectively, with p-vales virtually equal to zero). Hence, in the following, we primarily focus in a second set of estimates based on the MG-CCE approach. For the MG-CCE we consider the prices set by all competitors existing at each moment of time within a determined radius (regardless of whether or not they 
reported prices at another time during the period studied). Specifically, we show the empirical results by taking into account retail prices set by competitors within a 200meter radius. ${ }^{9}$

Some interesting evidence is provided by the estimated long-run coefficients, which are quite similar in the two metropolitan areas. The coefficients for dummies, where the corresponding variable for Sundays is excluded, are very significant. We reject the null hypothesis of equality across all daily effects, which reveal some seasonal patterns in pricing behavior. More specifically, retail prices decrease significantly on Mondays and climb again at the beginning of the weekend. This outcome is highly consistent with recent reports from the Spanish National Energy Commission. ${ }^{10}$ Although the hypothesis of complete pass-through is only statistically supported for the Madrid metropolitan area, the corresponding estimated coefficients indicated that it is close to unity for both areas. That is, a rise (fall) in wholesale fuel prices would imply an increase (decrease) of similar magnitude in retail fuel prices.

The regression coefficient associated to the error correction term $(\theta)$ is statistically significant and negative regardless of the metropolitan area considered. As expected, this outcome predicts that retail prices return toward their long-run equilibrium after a wholesale price shock. In particular, the estimated values indicate that deviations from such equilibrium are corrected by an adjustment of $12.4 \%$ per day in the case of the Madrid area and of $11.2 \%$ per day in the case of the Barcelona area. These convergence coefficients also allow us to approximate the half-life, which summarizes the speed of mean reversion. In our case, the number of days needed to reduce a deviation from the long-run equilibrium by one half is about six days for both geographical areas.

A more precise interpretation of the dynamic adjustment process after an oil price shock also requires the short-run coefficients to be taken into consideration. Thus, we analyze the CRFs, which provide an overview of the adjustment process after a shock until the level of equilibrium and, therefore, the long-run pass-through, is reached. Moreover, because the short run coefficients are divided according to increases or decreases in wholesale fuel prices, from these functions it will be possible to evaluate the presence of

\footnotetext{
${ }^{9}$ A robustness test was performed using an alternative matrix of distances corresponding to radii of 100 and 300 meters. The results, which do not differ substantially from those presented in Table 3, are available from the authors upon request.

${ }^{10}$ See, for example, the report for 2013 at the website www.cne.es/cne/doc/publicaciones/cne76_13.pdf.
} 
price response asymmetries, as we discussed in Section 2. In the charts of Figure 1, we focus on the CRFs and their confidence intervals in accordance with our estimates. ${ }^{11}$ The charts show that the CRFs are, in general, very similar for the two metropolitan areas. The difference between estimated cumulative responses to rises and falls in wholesale prices is also represented in these charts. As we can see, differences over time are generally positive until the price level equilibrium is reached, indicating that the estimated response to an increase of wholesale prices is usually faster. This adjustment pattern, known as the "rockets and feathers" phenomenon, should be statistically tested to draw conclusions with sufficient confidence. For this purpose we consider $95 \%$ confidence intervals. The evolution of intervals suggests that this phenomenon prevails until the eleventh day after a shock. Thereafter, the difference between cumulative responses to positive and negative shocks is not significant.

[Please insert Figure 1 here]

\subsection{From aggregated data}

The presence of behavioral heterogeneity found in subsection 3.1. clearly suggests some preference for estimates from disaggregated data since, otherwise, the estimated coefficients may be somewhat biased. However, in order to investigate the extent to which our findings are sensitive to typical aggregation over micro units, now we analyze time series derived from the cross-sectional average of retail prices.

The empirical results from the OLS procedure are shown in Table 4. The models selected from the AIC are free of autocorrelation according to the Breusch-Godfrey test. As in the above long-run estimates, a significant daily seasonality in pricing behavior is revealed and the cost pass-through is close to unity for both areas. Additionally, the regression coefficient of the error correction term $(\theta)$ is statistically significant and negative for both metropolitan areas. Now, deviations from the equilibrium between wholesale and retail prices are corrected by a factor of between $4 \%$ and $6 \%$ per day, approximately, depending on the geographical zones considered. The estimated time taken to reach half-life is about 12 days for the Madrid area and 15 days for the Barcelona area.

\footnotetext{
${ }^{11}$ The CRFs for the basic MG panel methodology are presented for both areas in Appendix A. The graphs show that the estimated retail price response after a shock is fairly similar regardless of the panel approach applied.
} 
[Please insert Table 4 here]

As in Subsection 3.2, we also take into account the short-run estimates in an attempt to better understand the dynamics of price responses and to test for asymmetries. The charts of Figure 2 show the CRFs and their corresponding intervals at the $95 \%$ confidence level. The graphical results are broadly consistent for both metropolitan areas. The difference between estimated cumulative responses to positive and negative shocks is also represented. Now, although this difference might seem remarkable, we cannot reject the hypothesis of price response symmetries.

[Please insert Figure 2 here]

\subsection{Comparison of results}

Two aspects should be taken into account when, as is usual in this research area, aggregated data on individual fuel stations are used: the estimated coefficients are potentially biased and the statistical inference can be affected.

Our results show that cross-sectional aggregation of retail fuel prices may largely overstate the dynamic process. On the one hand, we can see that the estimated speed toward long-run equilibrium is slower and, then, the estimated time to reach the half-life is longer. Specifically, it is extended by about six days for the Madrid metropolitan area, and nine days for the Barcelona metropolitan area. On the other hand, we can see how data aggregation also increases the short-run dynamics through the larger number of selected lags. More specifically, the selected number of lags for wholesale prices goes from eight to nine in the final specification of the models for both geographical contexts. $^{12}$

A straightforward comparison of the overall dynamics displayed between disaggregated and aggregated data may be made by using the CRFs. Figure 3 shows the CRFs, for both types of data, related to the corresponding estimated pass-through in the long term where the level of price equilibrium should be reached. By assuming that the microrelations are properly specified, divergence between the two dynamics would provide an approximation to estimation bias arising from the aggregation. In general, the relative cumulative response is lower from the aggregated data and the dynamics toward

\footnotetext{
${ }^{12}$ The price stickiness also increases in the case of the Barcelona metropolitan area when aggregated data are used.
} 
equilibrium is amplified over time. Note that this implies, as in the studied cases, that the potential difference in price responses may also be artificially expanded over time (Figures 1 and 2).

[Please insert Figure 3 here]

Although aggregation allows an extension of the differences over time, it does not necessarily yield results on asymmetries. In fact, besides the problem related to the estimated coefficients, we found that the power of test is considerably lower. A drastic reduction in the number of observations available after the aggregation of micro units seems to be the main driver of increases in the standard errors of estimated coefficients causing, in the end, relatively wide confidence bands in our case. ${ }^{13}$ In other words, we must take into account that when data from the micro units were used the number of observations was much higher (i.e., 254,700 for Madrid and 166,500 for Barcelona), even though the sample size for the aggregated data is fairly standard (i.e., 900 observations).

\section{Concluding remarks}

Most empirical studies on fuel price responses are based on aggregated data on fuel stations and, therefore, the conclusions are founded on the implicit assumption of a "representative agent". In the present paper, we relaxed this standard assumption. Unlike others papers in the field, we used a set of daily data for a large number of individual fuel stations. We therefore assume that the daily data help to avoid temporal aggregation bias. Further, data for micro units allowed us to explore the possible improvements of estimations on the empirical approach typically used in this research field. The study was based on statistical information from Spanish fuel stations operating in the metropolitan areas of Madrid and Barcelona. As these metropolitan areas belong to a context for which findings are somewhat inconclusive, the evidence offered could also have a special interest for the literature. To work with data for micro units we applied two alternative methodologies: Pesaran and Smith's (1995) mean group (MG), and Pesaran's (2006) mean group with common correlated effects estimator (MG-CCE). The results from the two panel methodologies are quite similar. However, because we found some evidence of cross-sectional dependence, we opted to

13 Another reason could be some change in the variance of regressions under aggregation (see, for example, Garrett, 2003). 
focus mainly on the empirical results from the MG-CCE. Moreover, the outcomes for both metropolitan areas are broadly consistent.

We found that the heterogeneity of behavior matters in the specification of our models. Thus, as expected from the econometric literature, when the behavior heterogeneity of fuel stations is not considered, it would lead to notable bias in fuel price adjustments. Specifically, the speed of adjustment toward the equilibrium is artificially slowed down, which is consistent with evidence obtained for others products for which price transmission has been studied (e.g., Pelzman, 2005; Cramon-Taubedel et al., 2006). This result could help to explain the surprising permanence of shocks in many studies in this research area. Overstating the time taken to reach the level of equilibrium may, understandably, also cause an expansion over time of the possible differences between responses to positive and negative shocks. In spite of this, the empirical evidence on asymmetries also depends on statistical inference.

The null hypothesis of symmetry cannot be supported when data for micro units are used. More specifically, our results suggested the existence of the "rockets and feathers" phenomenon basically for the first week after a shock. However, after aggregation of our individual time series, we obtained no evidence of this phenomenon although the number of observations available was still within the standard for this type of study. This could explain why sometimes the presence of "rockets and feathers" has not been unambiguously concluded, even though it could actually be relevant. Hence, panel data information not only allows us to consider behavioral heterogeneity, but it also provides more degrees of freedom and sample variability to improve the efficiency of the corresponding estimates. We hope that this empirical experiment encourages, as far as possible, the use of micro data to measure fuel price responses and testing asymmetries.

\section{Acknowledges}

The authors wish to thank members of the Department of Economics at the University of Sheffield (UK) for their comments and suggestions during the research stay of Jordi Ripollés in fall 2013. Financial support from the EU and the Spanish Ministry of Economy and Competitiveness (ECO2011-28155), and the Generalitat Valenciana (VALI+D, ACIF/2010 and BEFPI/2013) is also acknowledged. 


\section{References}

Al-Gudhea, S., Kenc, T. and Dibooglu, S. (2007). 'Do retail gasoline prices rise more readily than they fall?: A threshold cointegration approach', Journal of Economics and Business, Vol. 59, pp. 560-574.

Bachmeier, L. J. and Griffin, J. M. (2003). 'New evidence on asymmetric gasoline price responses', Review of Economics and Statistics, Vol. 85, pp. 772-776.

Bacon, R. W. (1991). 'Rockets and feathers: The asymmetric speed of adjustment of UK retail gasoline prices to cost changes', Energy Economics, Vol. 13, pp. 211-218.

Balaguer, J. and Ripollés, J. (2012). 'Testing for price response asymmetries in the Spanish fuel market. New evidence from daily data', Energy Economics, Vol. 34, pp. 2066-2071.

Bettendorf, L., Van der Geest, S. and Varkevisser, M. (2003). 'Price asymmetry in the Dutch retail gasoline market', Energy Economics, Vol. 25, pp. 669-689.

Bettendorf, L., Van der Geest, S. A. and Kuper, G. H. (2009). 'Do daily retail gasoline prices adjust asymmetrically?' Journal of Applied Statistics, Vol. 36, pp. 385-397.

Borenstein, S., Cameron, A. C. and Gilbert, R. (1997). 'Do gasoline prices respond asymmetrically to crude oil price changes?' The Quarterly Journal of Economics, Vol. 112, pp. 305-339.

Breitung, J. and Das, S. (2005). 'Panel unit root tests under cross-sectional dependence', Statistica Neerlandica, Vol. 59, pp. 414-433.

Breusch, T. S. and Godfrey, L. G. (1981). A Review of Recent Work on Testing for Autocorrelation in Dynamic Economic Models, Macroeconomic analysis: Essays in Macroeconomics and Econometrics, edited by Currie, D.A., Nobay, R. and Peel, D., London: Groom Helm, pp. 63-105.

Breusch, T. S. and Pagan, A. R. (1980). 'The Lagrange multiplier test and its applications to model specification in econometrics', Review of Economics Studies, Vol. 47, pp. 239-253. 
Broda, C. and Weinstein, D. E. (2008). Understanding International Price Differences Using Barcode Data, Working paper no. 14017, National Bureau of Economic Research, Cambridge, MA.

Contín-Pilart, I., Correljé, A. F. and Palacios, M. B. (2009). 'Competition, regulation, and pricing behaviour in the Spanish retail gasoline market', Energy Policy, Vol. 37, pp. 219-228.

Cramon-Taubadel S., Loy, J. P. and Meyer, J. (2006). 'The impact of cross-sectional data aggregation on the measurement of vertical price transmission: An experiment with German food prices', Agribusiness, Vol. 22, pp. 505-522.

Eberhardt, M. and Teal, F. (2012). 'No mangoes in the tundra: Spatial heterogeneity in agricultural productivity analysis', Oxford Bulletin of Economics and Statistics, Vol. 75, pp. 914-939.

Engle, R. F. and Granger, C. W. J. (1987). 'Co-integration and error correction: representation, estimation, and testing', Econometrica, Vol. 55, pp. 251-276.

Galeotti, M., Lanza, A. and Manera, M. (2003). 'Rockets and feathers revisited: an international comparison on European gasoline market', Energy Economics, Vol. 25, pp. 175-190.

García Ballesteros, A. and Sanz Berzal, B. (2002). Atlas de la Comunidad de Madrid en el umbral del siglo XXI, Comunidad de Madrid y Universidad Complutense.

Garrett, T. A. (2003). 'Aggregated versus disaggregated data in regression analysis: implications for inference', Economic Letters, Vol. 81, 61-65.

Geweke, J. (1978). 'Temporal aggregation in the multiple regression model', Econometrica, Vol. 46, pp. 643-661.

Granger, C. W. J. (1980). 'Long memory relationships and the aggregation of dynamic models', Journal of Econometrics, Vol. 14, pp. 227-238.

Imbs, J., Mumtaz, H., Ravn, M. O. and Rey, H. (2005). 'PPP strikes back: Aggregation and the real exchange rate', The Quarterly Journal of Economics, Vol. 120, pp. 1-43.

Kuper, G. H. (2012). 'Inventories and upstream gasoline price dynamics', Energy Economics, Vol. 34, pp. 208-214. 
Lippi, M. (1988). 'On the dynamic shape of aggregated error correction models', Journal of Economic Dynamics and Control, Vol. 12, pp. 561-585.

MacKinnon, J. G. (1996). 'Numerical distribution functions for unit root and cointegration tests', Journal of Applied Econometrics, Vol. 11, pp. 601-618.

Noel, M. (2009). 'Do retail gasoline prices respond asymmetrically to cost shocks? The influence of Edgeworth Cycles', The RAND Journal of Economics, Vol. 40, pp. 582595.

Peltzman, S. (2000). 'Prices rise faster than they fall', Journal of Political Economy, Vol. 108, pp. 466-502.

Perdiguero-García, J. (2013). 'Symmetric or asymmetric oil prices? A meta-analysis approach', Energy Policy, Vol. 57, pp. 389-397.

Pesaran, M.H., and Smith, R. (1995). 'Estimating long-run relationships from dynamic heterogeneous panels', Journal of Econometrics, Vol. 68, pp. 79-113.

Pesaran, M. H., Shin, Y. and Smith, R. P. (1999). 'Pooled mean group estimation of dynamic heterogeneous panels', Journal of the American Statistical Association, Vol. 94, pp. 621-634.

Pesaran, M. H. (2003). 'Aggregation of linear dynamic models: An application to lifecycle consumption models under habit formation', Economic Modelling, Vol. 20, pp. $383-415$.

Pesaran, M. H. (2006). 'Estimation and inference in large heterogeneous panels with a multifactor error structure', Econometrica 74, 967-1012.

Pesaran, M. H. and Tosetti, E. (2011). 'Large panels with common factors and spatial correlation', Journal of Econometrics, Vol. 161, pp. 182-202.

Phillips, P. C. B. and Perron, P. (1988). 'Testing for a unit root in time series regression', Biometrika, Vol. 75, pp. 335-346.

Powers, N. J. (1995). 'Sticky short-run prices and vertical pricing: Evidence from the market for iceberg lettuce', Agribusiness, Vol. 11, pp. 57-75. 
Radchenko, S. (2005). 'Lags in the response of gasoline prices to changes in crude oil prices: the role of short-term and long-term shocks', Energy Economics, Vol. 27, pp. 573-602.

Robertson, R., Kumar, A. and Dutkowsky, D. H. (2009). 'Purchasing power parity and aggregation bias for a developing country: The case of Mexico', Journal of Development Economics, Vol. 90, pp. 237-243.

Stoker, T. M. (1993). 'Empirical approaches to the problem of aggregation over individuals', Journal of Economic Literature, Vol. 31, pp. 1827-1874.

Theil, H. (1954). Linear Aggregation of Economic Relations, Amsterdam, NorthHolland Publishing Company.

Trivedi, P. K. (1985). 'Distributed lags, aggregation and compounding: Some econometric implications', The Review of Economic Studies, Vol. 52, pp. 19-35.

Valadkhani, A. (2013). 'Modelling the terminal gate prices of unleaded petrol in Australia', Economic Modelling, Vol. 33, pp. 233-243.

Wlazlowski, S., Giulietti, M., Binner, J. and Milas, C. (2012). 'Price transmission in the EU wholesale petroleum markets', Journal of Business and Economic Statistics, Vol. 30, pp. $165-172$.

Westerlund, J. (2007). 'Testing for error correction in panel data', Oxford Bulletin of Economics and Statistics, Vol. 69, pp. 709-748.

Wooldridge, J. M. (2002). Econometric Analysis of Cross Section and Panel Data, MIT Press, Cambridge, MA.

\section{Appendix A}

[Please insert Figure A1 here] 
Table 1. Selected papers focused on retail fuel price responses

\begin{tabular}{|c|c|c|c|c|c|c|}
\hline Authors & $\begin{array}{l}\text { Origin of the } \\
\text { price shock }\end{array}$ & Country & Time period & Frequency & Methodology & $\begin{array}{l}\text { Half-life } \\
\text { in weeks }\end{array}$ \\
\hline \multirow[t]{2}{*}{ Borenstein et al. (1997) } & Wholesale & US & 1986-1992 & Biweekly & ECM & 5.67 \\
\hline & Crude & & & & & 8.49 \\
\hline \multirow[t]{10}{*}{ Galeotti et al. (2003) } & Wholesale & Germany & $1985-1997$ & Monthly & $\mathrm{ECM}$ & 2.50 \\
\hline & & France & $1985-2000$ & & & 3.30 \\
\hline & & Italy & & & & 3.50 \\
\hline & & Spain & & & & 3.50 \\
\hline & & UK & & & & 3.30 \\
\hline & Crude & Germany & 1985-1997 & Monthly & $\mathrm{ECM}$ & 3.30 \\
\hline & & France & $1985-2000$ & & & 3.60 \\
\hline & & Italy & & & & 2.20 \\
\hline & & Spain & & & & 2.90 \\
\hline & & UK & & & & 11.00 \\
\hline \multirow[t]{2}{*}{ Radchenko (2005) } & Wholesale & US & 1991-2002 & Weekly & ECM with Markov-switching & 17.73 \\
\hline & Crude & & & & & 13.84 \\
\hline \multirow[t]{2}{*}{ Al-Gudhea et al. (2007) } & Wholesale & US & $1998-2003$ & Daily & $\begin{array}{l}\text { ECM with threshold } \\
\text { cointegration }\end{array}$ & 15.30 \\
\hline & Crude & & & & & 7.60 \\
\hline \multirow[t]{2}{*}{ Contin-Pilart et al. (2009) } & Wholesale & Spain & 1993-1998 & Weekly & $\mathrm{ECM}$ & 8.05 \\
\hline & & & 1998-2004 & & & 7.58 \\
\hline Balaguer and Ripollés (2012) & Wholesale & Spain & 2006-2009 & Daily & ECM with GARCH & 9.00 \\
\hline
\end{tabular}

Notes: ECM means Error Correction Model and GARCH is Generalized Autoregressive Conditional Heteroskedasticity. The persistence of shock is obtained by calculating the half-life of deviations from the long-run equilibrium (i.e., the natural logarithm of 0.5 divided by the value of the adjustment coefficient). In papers in which asymmetric long-run speed adjustment is allowed, we have reported the average of both measures for the half-life. 


\begin{tabular}{|c|c|c|c|c|}
\hline & \multicolumn{2}{|c|}{$\begin{array}{c}\text { Metropolitan area of } \\
\text { Madrid }\end{array}$} & \multicolumn{2}{|c|}{$\begin{array}{c}\text { Metropolitan area of } \\
\text { Barcelona } \\
\end{array}$} \\
\hline & Levels & First diff. & Levels & First diff. \\
\hline \multicolumn{5}{|l|}{ Unit root test } \\
\hline Breitung-Das test for disaggregated retail prices & -0.023 & $-27.856^{* * *}$ & 0.027 & $-28.717^{* * *}$ \\
\hline Phillips-Perron test for wholesale prices & -1.488 & $-26.056^{* * * *}$ & -1.488 & $-26.056^{* * * *}$ \\
\hline Phillips-Perron test for aggregated retail prices & -1.605 & $-20.576^{* * *}$ & -1.594 & $-19.849^{* * * *}$ \\
\hline \multicolumn{5}{|l|}{ Cointegration test } \\
\hline \multicolumn{5}{|l|}{ Westerlund tests (disaggregated retail prices) } \\
\hline $\mathrm{G}_{\tau}$ & \multicolumn{2}{|c|}{$-5.642^{* * *}$} & \multicolumn{2}{|c|}{$-5.916^{* * *}$} \\
\hline $\mathrm{G}_{\alpha}$ & \multicolumn{2}{|c|}{$-95.072^{* * *}$} & \multicolumn{2}{|c|}{$-104.124^{* * *}$} \\
\hline $\mathrm{P}_{\tau}$ & \multicolumn{2}{|c|}{$-110.533^{* * *}$} & \multicolumn{2}{|c|}{$-78.373^{* * *}$} \\
\hline $\mathrm{P}_{\alpha}$ & \multicolumn{2}{|c|}{$-113.349^{* * *}$} & \multicolumn{2}{|c|}{$-96.469^{* * *}$} \\
\hline Phillips-Perron test (aggregated retail prices) & \multicolumn{2}{|c|}{$-8.560^{* * *}$} & \multicolumn{2}{|c|}{$-8.323^{* * *}$} \\
\hline
\end{tabular}

Notes: We denote ${ }^{* * * *},{ }^{* *},{ }^{*}$ to indicate the rejection of the null hypotheses (unit root and non-cointegration) at the $1 \%, 5 \%$ and $10 \%$ significance levels, respectively. The Phillips-Perron test is performed by using the optimum lags obtained by the Newey-West procedure, whereas the lag order for the Breitung-Das and Westerlund tests are obtained by using the Akaike information criterion. Critical values for the PhillipsPerron and Breitung-Das tests are based on MacKinnon (1996) and Breitung and Das (2005), respectively. The Westerlund tests employ bootstrapped robust critical values based on 500 replications, where the Bartlett kernel bandwidth is set according to the $4(T / 100)^{2 / 9} \approx 7$ rule. 
Table 3. Regression results from cross-sectional disaggregated data

\begin{tabular}{|c|c|c|c|c|c|c|c|c|}
\hline \multirow{3}{*}{$\begin{array}{l}\text { Coefficients and } \\
\text { statistics } \\
\alpha\end{array}$} & \multicolumn{4}{|c|}{ Metropolitan area of Madrid } & \multicolumn{4}{|c|}{ Metropolitan area of Barcelona } \\
\hline & \multicolumn{2}{|c|}{$\mathrm{MG}$} & \multicolumn{2}{|c|}{ MG-CCE } & \multicolumn{2}{|c|}{$\mathrm{MG}$} & \multicolumn{2}{|c|}{ MG-CCE } \\
\hline & $0.086^{\text {***** }}$ & $(0.002)$ & $0.078^{* * * *}$ & $(0.006)$ & $0.090^{* * * *}$ & $(0.002)$ & $0.090^{* * * *}$ & $(0.030)$ \\
\hline$\gamma$ & $0.001^{* * *}$ & $(0.001)$ & $0.001^{* * *}$ & $(0.001)$ & $0.001^{* *}$ & $(0.001)$ & $0.001^{* *}$ & $(0.001)$ \\
\hline$\vartheta_{1}$ & $-0.003^{* * *}$ & $(0.001)$ & $-0.002^{* * *}$ & $(0.001)$ & $-0.002^{* * *}$ & $(0.001)$ & $-0.002^{* * *}$ & $(0.001)$ \\
\hline$\vartheta_{2}$ & $-0.003^{* * *}$ & $(0.001)$ & $-0.002^{* * *}$ & $(0.001)$ & $-0.003^{* * *}$ & $(0.002)$ & $-0.003^{* * *}$ & $(0.002)$ \\
\hline$\vartheta_{3}$ & $-0.003^{* * *}$ & $(0.001)$ & $-0.002^{* * *}$ & $(0.001)$ & $-0.003^{* * *}$ & $(0.001)$ & $-0.003^{* * *}$ & $(0.002)$ \\
\hline$\vartheta_{4}$ & $-0.001^{* * *}$ & $(0.001)$ & $-0.001^{* * *}$ & $(0.001)$ & $-0.001^{* * *}$ & $(0.002)$ & $-0.001^{* * * *}$ & $(0.002)$ \\
\hline$\vartheta_{5}$ & $0.001^{* * *}$ & $(0.001)$ & $0.001^{* * *}$ & $(0.001)$ & $0.001^{* * *}$ & $(0.002)$ & $0.001^{* * *}$ & $(0.002)$ \\
\hline$\vartheta_{6}$ & $0.001^{* * *}$ & $(0.001)$ & $0.001^{* * *}$ & $(0.001)$ & $0.002^{* * *}$ & $(0.001)$ & $0.002^{* * *}$ & (0.001) \\
\hline$\phi$ & $1.121^{* * * *}$ & $(0.003)$ & $1.017^{* * *}$ & $(0.071)$ & $1.116^{* * * *}$ & $(0.004)$ & $1.092^{* * *}$ & $(0.030)$ \\
\hline$\beta_{1}^{+}$ & $-0.117^{* * *}$ & $(0.004)$ & $-0.116^{* * *}$ & $(0.004)$ & $-0.088^{* * *}$ & $(0.006)$ & $-0.087^{* * *}$ & (0.006) \\
\hline$\beta_{1}^{-}$ & $-0.199^{* * *}$ & $(0.005)$ & $-0.198^{* * *}$ & $(0.005)$ & $-0.185^{\text {*** }}$ & $(0.007)$ & $-0.184^{* * *}$ & (0.007) \\
\hline$\beta_{2}^{+}$ & $-0.039^{* * *}$ & (0.003) & $-0.038^{* * * *}$ & $(0.003)$ & $-0.035^{* * *}$ & $(0.003)$ & $-0.035^{* * *}$ & $(0.002)$ \\
\hline$\beta_{2}^{-}$ & $-0.107^{* * *}$ & (0.004) & $-0.106^{* * *}$ & $(0.004)$ & $-0.103^{* * *}$ & $(0.004)$ & $-0.102^{* * *}$ & (0.004) \\
\hline$\beta_{3}^{+}$ & $-0.093^{* * *}$ & (0.004) & $-0.093^{* * * *}$ & $(0.004)$ & $-0.073^{\text {*** }}$ & $(0.005)$ & $-0.073^{* * *}$ & $(0.005)$ \\
\hline$\beta_{3}^{-}$ & $-0.019^{* * * *}$ & (0.003) & $-0.018^{* * * *}$ & $(0.003)$ & $-0.023^{* * * *}$ & $(0.004)$ & $-0.023^{* * * *}$ & (0.004) \\
\hline$\beta_{4}^{+}$ & $-0.073^{* * *}$ & (0.003) & $-0.073^{* * *}$ & $(0.003)$ & $-0.053^{* * *}$ & $(0.004)$ & $-0.053^{* * *}$ & $(0.004)$ \\
\hline$\beta_{4}^{-}$ & $-0.046^{* * *}$ & (0.004) & $-0.046^{* * *}$ & $(0.004)$ & $-0.032^{* * *}$ & $(0.003)$ & $-0.032^{* * *}$ & (0.003) \\
\hline$\beta_{5}^{+}$ & $-0.093^{* * *}$ & $(0.004)$ & $-0.093^{* * *}$ & $(0.004)$ & $-0.080^{* * *}$ & $(0.005)$ & $-0.080^{* * *}$ & $(0.005)$ \\
\hline$\beta_{5}^{-}$ & 0.004 & $(0.003)$ & 0.004 & $(0.003)$ & 0.003 & $(0.003)$ & 0.003 & $(0.003)$ \\
\hline$\beta_{6}^{+}$ & $-0.024^{* * *}$ & $(0.003)$ & $-0.024^{* * *}$ & $(0.003)$ & $-0.022^{* * *}$ & (0.004) & $-0.022^{* * *}$ & (0.004) \\
\hline$\beta_{6}^{-}$ & $-0.041^{* * *}$ & $(0.004)$ & $-0.041^{* * *}$ & $(0.004)$ & $-0.044^{* * *}$ & $(0.005)$ & $-0.044^{* * *}$ & $(0.005)$ \\
\hline$\beta_{7}^{+}$ & $0.072^{* * *}$ & $(0.003)$ & $0.072^{* * *}$ & $(0.003)$ & $0.065^{* * *}$ & $(0.004)$ & $0.065^{* * *}$ & $(0.004)$ \\
\hline$\beta_{7}^{-}$ & $0.113^{* * * *}$ & $(0.005)$ & $0.113^{* * *}$ & $(0.005)$ & $0.104^{* * * *}$ & $(0.007)$ & $0.103^{* * *}$ & (0.006) \\
\hline$\beta_{8}^{+}$ & & & & & 0.002 & $(0.003)$ & 0.002 & $(0.003)$ \\
\hline$\beta_{8}^{-}$ & & & & & 0.001 & $(0.003)$ & 0.001 & (0.003) \\
\hline$\delta_{0}^{+}$ & $0.011^{* * * *}$ & $(0.004)$ & $0.011^{* * *}$ & $(0.004)$ & $0.015^{* * *}$ & $(0.005)$ & $0.015^{* * *}$ & $(0.005)$ \\
\hline$\delta_{0}^{-}$ & -0.004 & $(0.005)$ & -0.004 & $(0.005)$ & $0.015^{* * *}$ & $(0.006)$ & $0.014^{* *}$ & (0.006) \\
\hline$\delta_{1}^{+}$ & $-0.088^{* * *}$ & $(0.003)$ & $-0.087^{* * *}$ & $(0.003)$ & $-0.085^{* * *}$ & $(0.004)$ & $-0.084^{* * * *}$ & (0.004) \\
\hline$\delta_{1}^{-}$ & $-0.108^{* * *}$ & $(0.005)$ & $-0.107^{* * *}$ & $(0.005)$ & $-0.110^{* * *}$ & $(0.005)$ & $-0.109^{* * *}$ & $(0.005)$ \\
\hline$\delta_{2}^{+}$ & $0.168^{* * *}$ & $(0.012)$ & $0.168^{* * *}$ & $(0.012)$ & $0.134^{* * *}$ & $(0.016)$ & $0.135^{* * *}$ & (0.016) \\
\hline$\delta_{2}^{-}$ & $0.034^{* * *}$ & $(0.008)$ & $0.035^{* * *}$ & $(0.008)$ & $0.027^{* * *}$ & (0.009) & $0.028^{* * *}$ & (0.009) \\
\hline$\delta_{3}^{+}$ & $0.155^{* * *}$ & $(0.005)$ & $0.155^{* * *}$ & $(0.005)$ & $0.133^{* * *}$ & $(0.007)$ & $0.134^{* * *}$ & (0.007) \\
\hline$\delta_{3}^{-}$ & $0.051^{* * *}$ & $(0.005)$ & $0.051^{* * *}$ & $(0.005)$ & $0.036^{* * *}$ & $(0.006)$ & $0.036^{* * *}$ & (0.006) \\
\hline$\delta_{4}^{+}$ & $0.128^{* * * *}$ & $(0.004)$ & $0.127^{* * *}$ & (0.004) & $0.100^{* * *}$ & (0.006) & $0.100^{* * *}$ & (0.006) \\
\hline$\delta_{4}^{-}$ & $0.131^{* * *}$ & $(0.007)$ & $0.132^{* * *}$ & $(0.007)$ & $0.097^{* * *}$ & $(0.009)$ & $0.098^{* * *}$ & (0.009) \\
\hline$\delta_{5}^{+}$ & $0.109^{* * *}$ & $(0.004)$ & $0.108^{* * *}$ & $(0.004)$ & $0.091^{* * *}$ & $(0.005)$ & $0.091^{* * *}$ & (0.005) \\
\hline$\delta_{5}^{-}$ & $0.180^{* * *}$ & $(0.004)$ & $0.180^{* * *}$ & $(0.004)$ & $0.158^{* * *}$ & $(0.007)$ & $0.157^{* * *}$ & (0.007) \\
\hline$\delta_{6}^{+}$ & $0.105^{* * *}$ & $(0.003)$ & $0.104^{* * *}$ & $(0.003)$ & $0.089^{* * *}$ & $(0.005)$ & $0.089^{* * *}$ & $(0.005)$ \\
\hline$\delta_{6}^{-}$ & $0.173^{* * *}$ & $(0.003)$ & $0.173^{* * *}$ & $(0.003)$ & $0.147^{* * *}$ & $(0.005)$ & $0.147^{* * *}$ & $(0.005)$ \\
\hline$\delta_{7}^{+}$ & $0.062^{* * *}$ & $(0.002)$ & $0.061^{* * *}$ & $(0.002)$ & $0.071^{* * *}$ & $(0.004)$ & $0.071^{* * *}$ & $(0.004)$ \\
\hline$\delta_{7}^{-}$ & $0.103^{* * *}$ & $(0.003)$ & $0.103^{* * *}$ & $(0.003)$ & $0.099^{* * *}$ & $(0.004)$ & $0.098^{* * *}$ & (0.004) \\
\hline$\delta_{8}^{+}$ & $0.149^{* * *}$ & $(0.004)$ & $0.149^{* * *}$ & $(0.004)$ & $0.128^{* * *}$ & $(0.006)$ & $0.128^{* * *}$ & (0.006) \\
\hline$\delta_{8}^{-}$ & $0.075^{\text {*** }}$ & $(0.002)$ & $0.075^{* * *}$ & $(0.003)$ & $0.084^{* * * *}$ & $(0.003)$ & $0.084^{* * *}$ & $(0.003)$ \\
\hline$\theta$ & $-0.113^{* * *}$ & $(0.002)$ & $-0.124^{* * *}$ & (0.009) & $-0.111^{* * *}$ & $(0.002)$ & $-0.112^{* * *}$ & $(0.003)$ \\
\hline Obs. $(N x T)$ & 254,700 & & 254,700 & & 166,500 & & 166,500 & \\
\hline Individuals $(N)$ & 283 & & 283 & & 185 & & 185 & \\
\hline$H_{0}: \vartheta_{q}=\vartheta, \forall_{q}$ & $8,846.16$ & {$[0.000]$} & $1,327.89$ & {$[0.000]$} & $5,168.49$ & {$[0.000]$} & $2,204.14$ & {$[0.000]$} \\
\hline$H_{0}: \phi=1$ & $1,711.17$ & {$[0.000]$} & 0.05 & [0.815] & $1,022.45$ & {$[0.000]$} & 11.98 & [0.001] \\
\hline
\end{tabular}

Notes: The standard errors are reported in parenthesis and p-values are presented in brackets. We use ${ }^{* * *}$, and ${ }^{*}$ to indicate significance of the coefficients at the $1 \%, 5 \%$ and $10 \%$ levels, respectively. The long-run elasticities from the cointegrating relationship are obtained by using the delta method. 
Table 4. Regression results from cross-sectional aggregated data

\begin{tabular}{|c|c|c|c|c|}
\hline \multirow{2}{*}{$\begin{array}{l}\text { Coefficients and } \\
\text { statistics } \\
\alpha \alpha\end{array}$} & \multicolumn{2}{|c|}{$\frac{\text { Metropolitan area of Madrid }}{\text { OLS }}$} & \multicolumn{2}{|c|}{$\frac{\text { Metropolitan area of Barcelona }}{\text { OLS }}$} \\
\hline & $0.078^{* * *}$ & $(0.025)$ & $0.079^{* * *}$ & $(0.028)$ \\
\hline$\gamma$ & $0.001^{* *}$ & $(0.001)$ & $0.001^{*}$ & $(0.001)$ \\
\hline$\vartheta_{1}$ & $-0.003^{*}$ & $(0.002)$ & $-0.002^{*}$ & $(0.002)$ \\
\hline$\vartheta_{2}$ & $-0.003^{*}$ & $(0.002)$ & $-0.003^{*}$ & $(0.002)$ \\
\hline$\vartheta_{3}$ & $-0.003^{*}$ & $(0.002)$ & $-0.003^{*}$ & $(0.002)$ \\
\hline$\vartheta_{4}$ & -0.001 & $(0.002)$ & -0.001 & $(0.002)$ \\
\hline$\vartheta_{5}$ & 0.001 & $(0.002)$ & 0.001 & $(0.002)$ \\
\hline$\vartheta_{6}$ & 0.001 & $(0.002)$ & 0.001 & $(0.002)$ \\
\hline$\phi$ & $1.122^{* * *}$ & $(0.051)$ & $1.116^{* * *}$ & $(0.057)$ \\
\hline$\beta_{1}^{+}$ & $0.176^{* * * *}$ & $(0.054)$ & $0.192^{* * *}$ & $(0.054)$ \\
\hline$\beta_{1}^{-}$ & -0.036 & $(0.049)$ & -0.008 & $(0.048)$ \\
\hline$\beta_{2}^{+}$ & $-0.084^{*}$ & $(0.054)$ & $-0.067^{*}$ & $(0.054)$ \\
\hline$\beta_{2}^{-}$ & $-0.070^{*}$ & $(0.049)$ & $-0.097^{* *}$ & $(0.048)$ \\
\hline$\beta_{3}^{+}$ & -0.063 & $(0.054)$ & -0.061 & $(0.055)$ \\
\hline$\beta_{3}^{-}$ & 0.013 & $(0.048)$ & 0.044 & $(0.047)$ \\
\hline$\beta_{4}^{+}$ & $-0.090^{*}$ & $(0.054)$ & 0.005 & $(0.054)$ \\
\hline$\beta_{4}^{-}$ & -0.026 & $(0.047)$ & -0.040 & $(0.047)$ \\
\hline$\beta_{5}^{+}$ & $-0.193^{* * *}$ & $(0.054)$ & $-0.198^{* * *}$ & $(0.055)$ \\
\hline$\beta_{5}^{-}$ & 0.020 & $(0.046)$ & 0.029 & $(0.046)$ \\
\hline$\beta_{6}^{+}$ & 0.062 & $(0.055)$ & 0.068 & $(0.056)$ \\
\hline$\beta_{6}^{-}$ & $-0.071^{*}$ & $(0.046)$ & $-0.091^{* *}$ & $(0.045)$ \\
\hline$\beta_{7}^{+}$ & $0.071^{*}$ & $(0.055)$ & $0.091^{*}$ & $(0.056)$ \\
\hline$\beta_{7}^{-}$ & $0.192^{*}$ & $(0.048)$ & $0.222^{* * * *}$ & $(0.046)$ \\
\hline$\beta_{8}^{+}$ & -0.018 & $(0.049)$ & -0.007 & $(0.050)$ \\
\hline$\beta_{8}^{-}$ & $-0.056^{*}$ & $(0.046)$ & $-0.061^{*}$ & $(0.045)$ \\
\hline$\delta_{0}^{+}$ & 0.011 & $(0.032)$ & 0.015 & $(0.029)$ \\
\hline$\delta_{0}^{-}$ & -0.027 & $(0.031)$ & -0.008 & $(0.028)$ \\
\hline$\delta_{1}^{+}$ & -0.043 & $(0.035)$ & -0.030 & $(0.031)$ \\
\hline$\delta_{1}^{-}$ & -0.032 & $(0.035)$ & -0.035 & $(0.031)$ \\
\hline$\delta_{2}^{+}$ & $0.213^{* * *}$ & $(0.035)$ & $0.188^{* * *}$ & $(0.031)$ \\
\hline$\delta_{2}^{-}$ & $0.089^{* *}$ & $(0.035)$ & $0.096^{* * *}$ & $(0.031)$ \\
\hline$\delta_{3}^{+}$ & $0.114^{* * *}$ & $(0.037)$ & $0.111^{* * *}$ & $(0.032)$ \\
\hline$\delta_{3}^{-}$ & $0.076^{* *}$ & $(0.036)$ & $0.063^{* *}$ & $(0.031)$ \\
\hline$\delta_{4}^{+}$ & $0.121^{* * * *}$ & $(0.037)$ & $0.098^{* * *}$ & $(0.033)$ \\
\hline$\delta_{4}^{-}$ & $0.135^{\text {*** }}$ & $(0.036)$ & $0.119^{* * *}$ & $(0.031)$ \\
\hline$\delta_{5}^{+}$ & $0.090^{* *}$ & $(0.037)$ & $0.080^{* *}$ & $(0.032)$ \\
\hline$\delta_{5}^{-}$ & $0.171^{* * * *}$ & $(0.036)$ & $0.160^{* * *}$ & $(0.031)$ \\
\hline$\delta_{6}^{+}$ & $0.094^{* * *}$ & $(0.037)$ & $0.070^{* *}$ & $(0.032)$ \\
\hline$\delta_{6}^{-}$ & $0.146^{* * * *}$ & $(0.036)$ & $0.130^{* * * *}$ & $(0.031)$ \\
\hline$\delta_{7}^{+}$ & $0.078^{* *}$ & $(0.036)$ & $0.078^{* *}$ & $(0.032)$ \\
\hline$\delta_{7}^{-}$ & $0.074^{* *}$ & $(0.035)$ & $0.076^{* *}$ & $(0.031)$ \\
\hline$\delta_{8}^{+}$ & $0.138^{* * * *}$ & $(0.036)$ & $0.112^{* * *}$ & $(0.032)$ \\
\hline$\delta_{8}^{-}$ & $0.049^{*}$ & $(0.035)$ & $0.060^{* *}$ & $(0.031)$ \\
\hline$\delta_{9}^{+}$ & $0.067^{*}$ & $(0.036)$ & $0.046^{*}$ & $(0.031)$ \\
\hline$\delta_{9}^{-}$ & -0.003 & $(0.034)$ & -0.014 & $(0.03)$ \\
\hline$\theta$ & $-0.057^{* * *}$ & $(0.014)$ & $-0.045^{* * *}$ & $(0.012)$ \\
\hline Obs. $(T)$ & 900 & & 900 & \\
\hline$H_{0}: \vartheta_{q}=\vartheta, \forall_{q}$ & 2.70 & {$[0.020]$} & 2.27 & {$[0.046]$} \\
\hline$H_{0}: \phi=1$ & 5.76 & {$[0.017]$} & 4.09 & {$[0.044]$} \\
\hline
\end{tabular}

Notes: The standard errors are reported in parenthesis and p-values are presented in brackets. We use ${ }^{* * *},{ }^{* *}$ and ${ }^{*}$ to indicate significance of the coefficients at the $1 \%, 5 \%$ and $10 \%$ levels, respectively. The long-run elasticities from the cointegrating relationship are obtained by using the delta method. 
Figure 1. CRFs from disaggregated data (based on MG-CCE)

a) Metropolitan area of Madrid

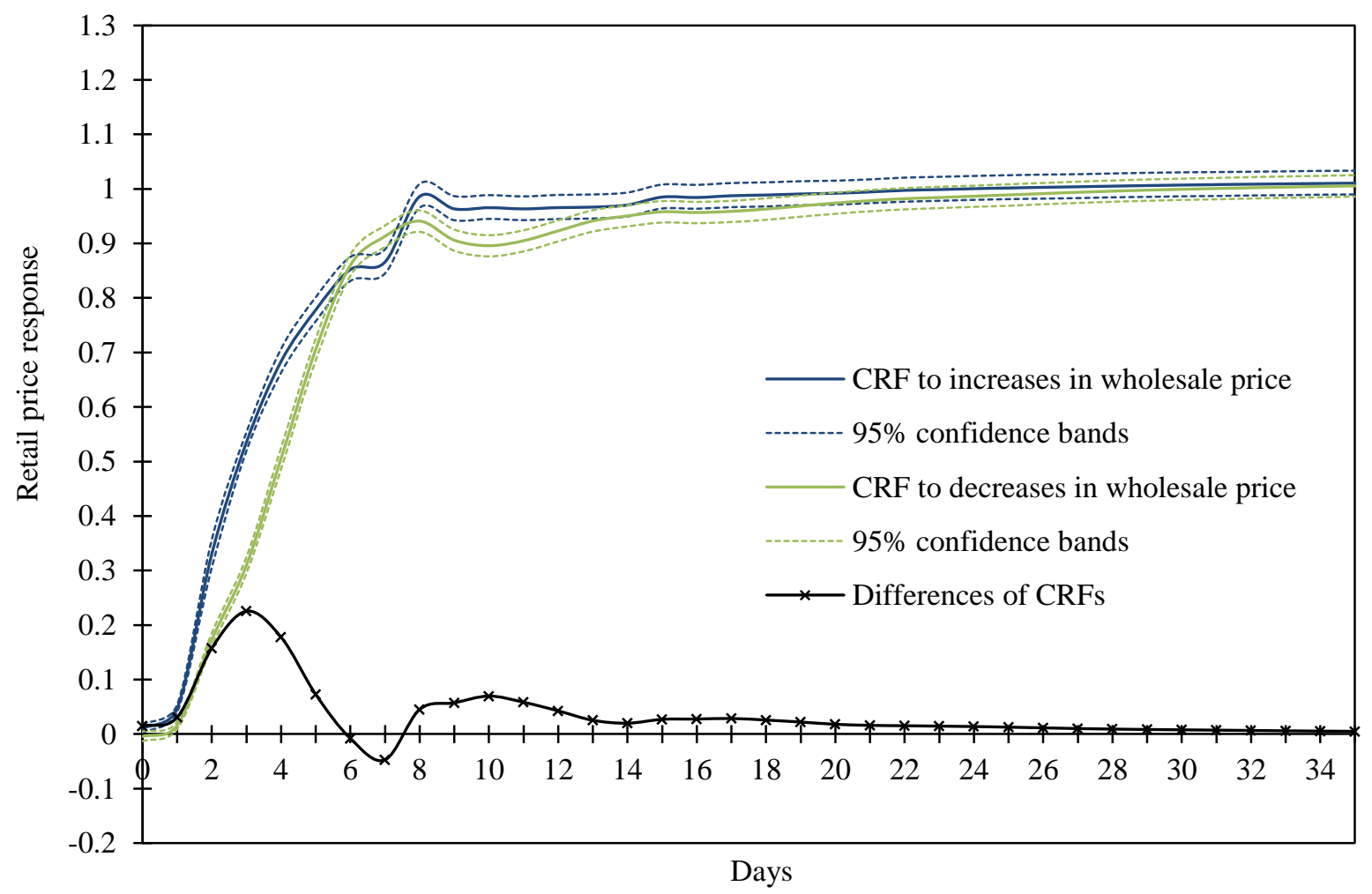

b) Metropolitan area of Barcelona

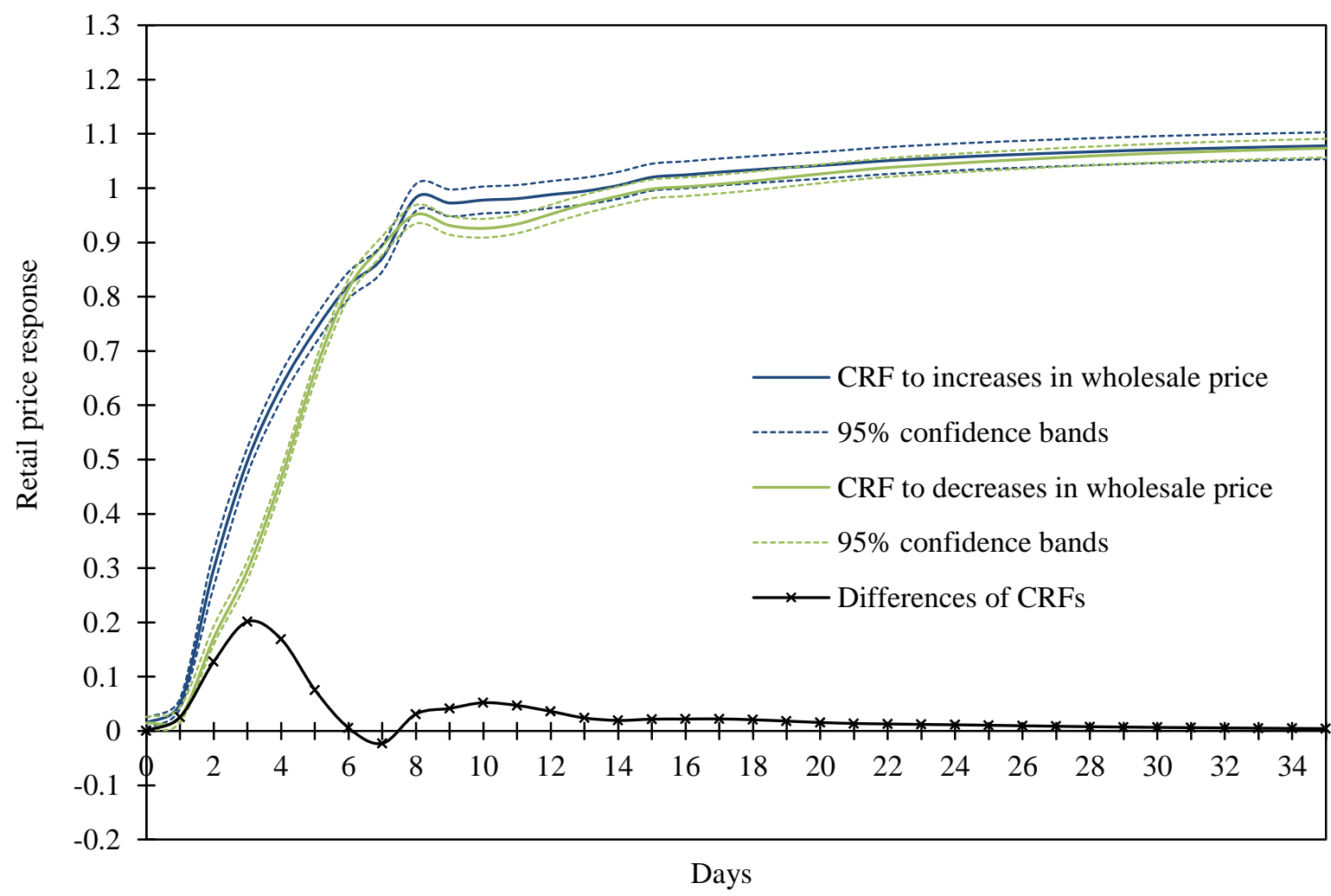


Figure 2. CRFs from aggregated data (based on OLS)

a) Metropolitan area of Madrid

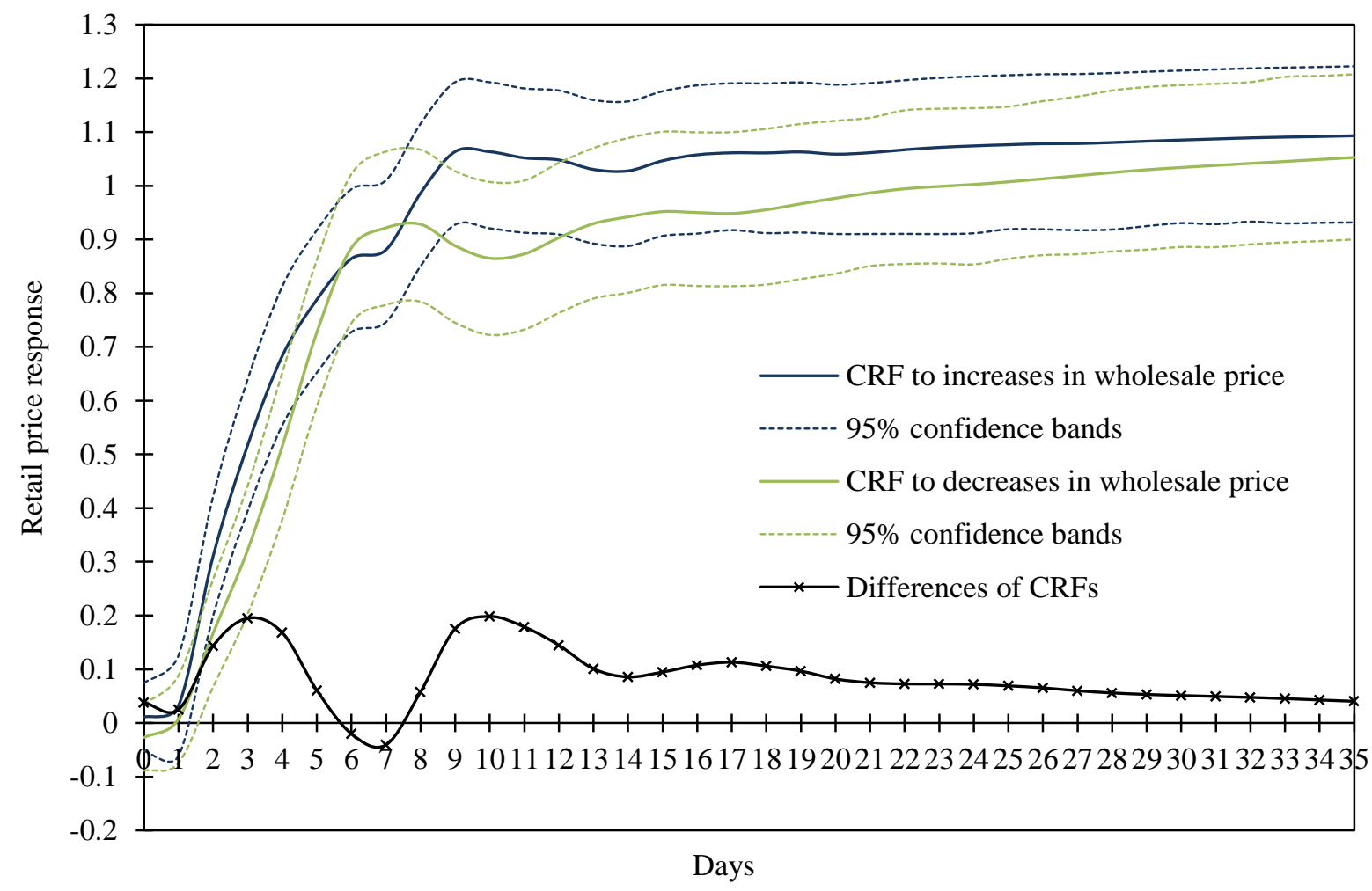

b) Metropolitan area of Barcelona

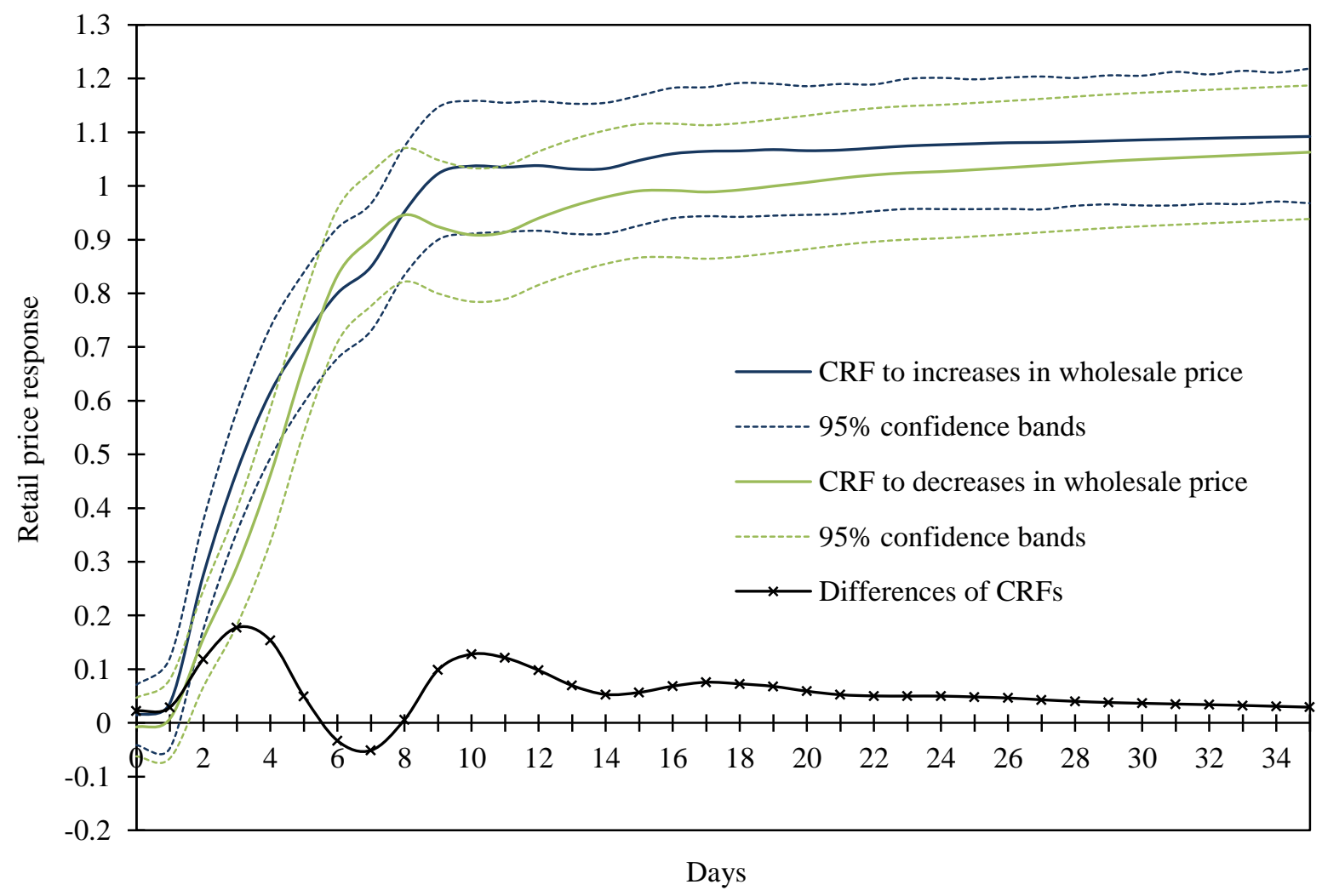


Figure 3. CRFs related to their corresponding pass-through in the long term

a) Metropolitan area of Madrid
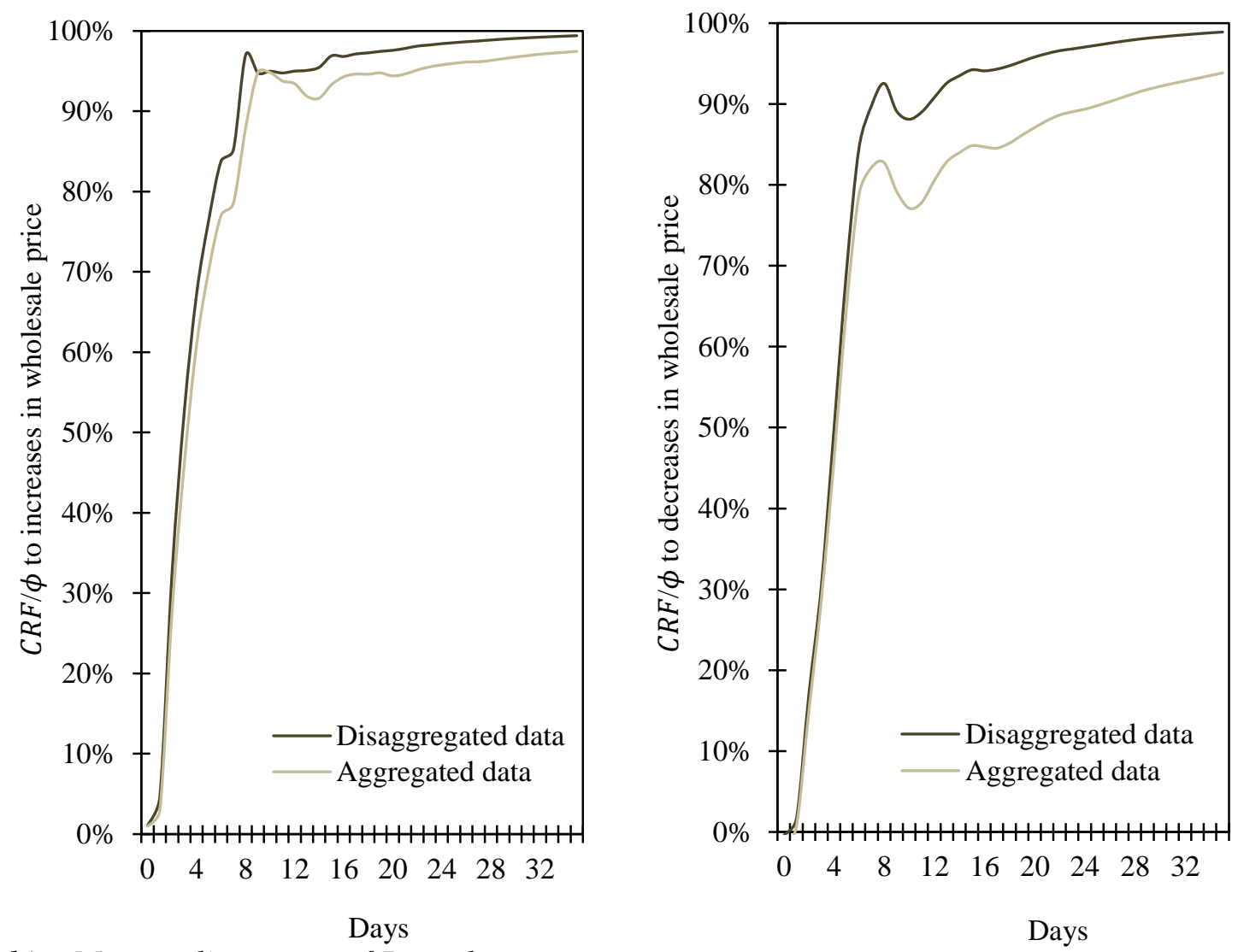

b) Metropolitan area of Barcelona
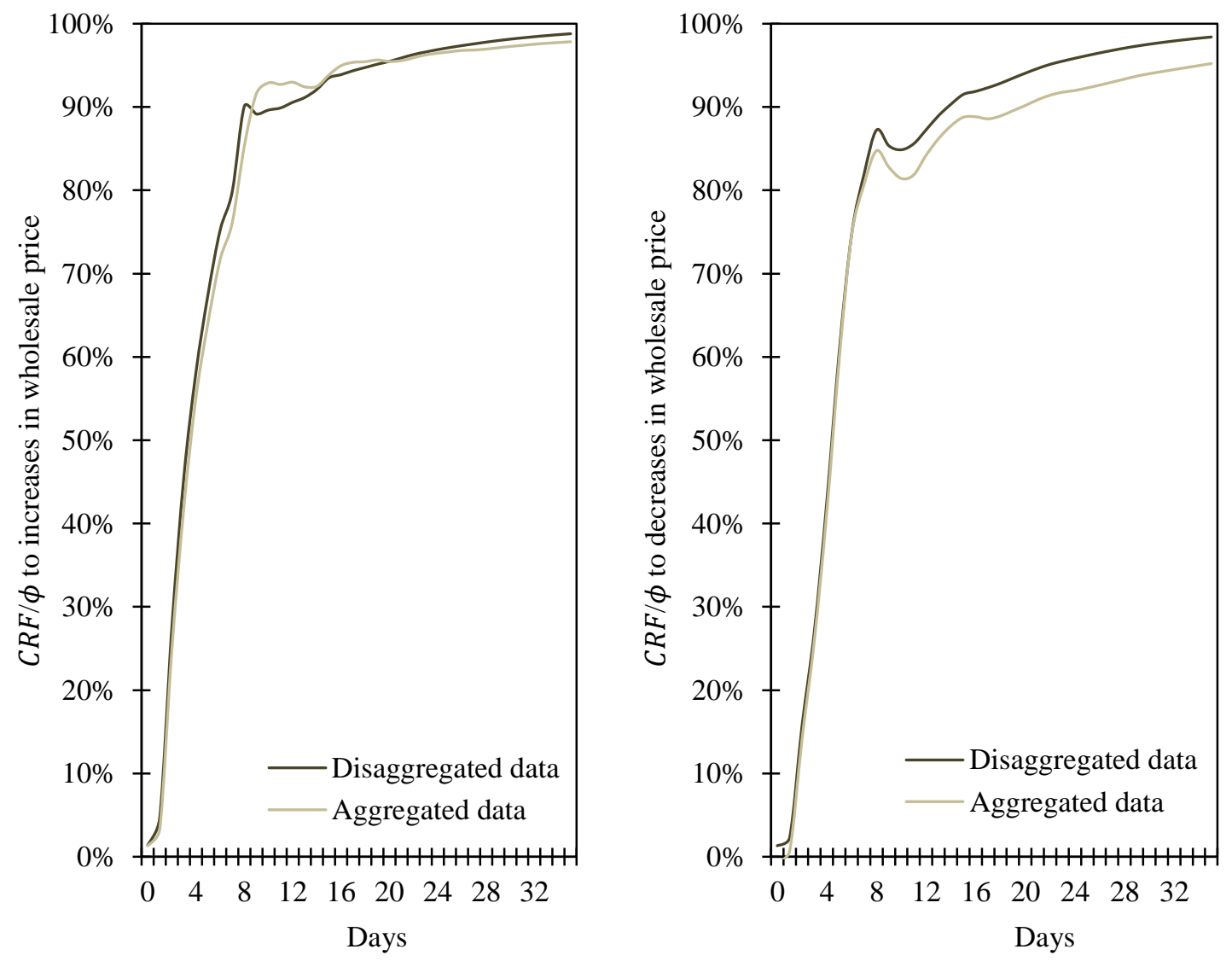
Figure A1. CRFs from disaggregated data (based on MG)

a) Metropolitan area of Madrid

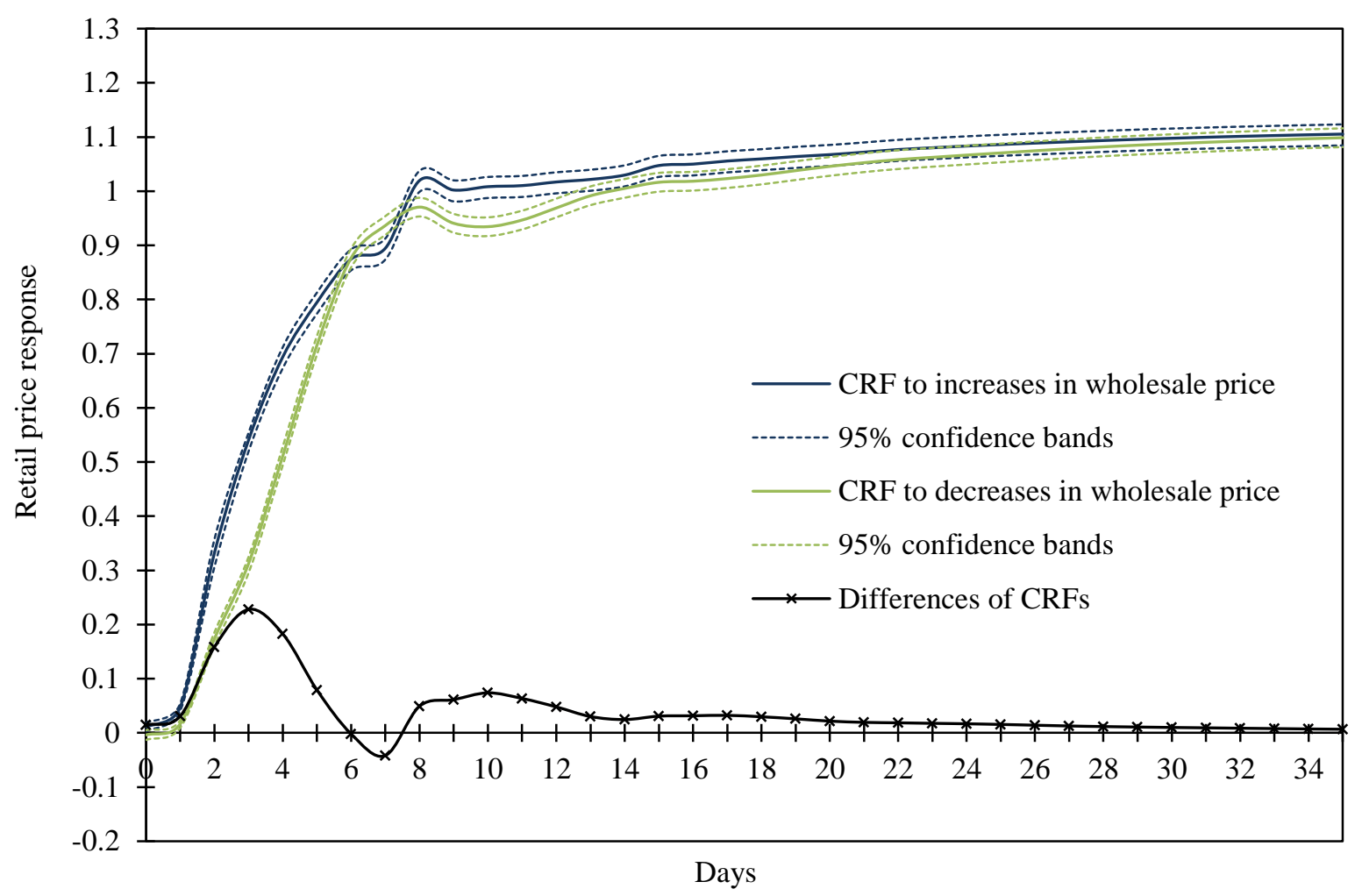

b) Metropolitan area of Barcelona

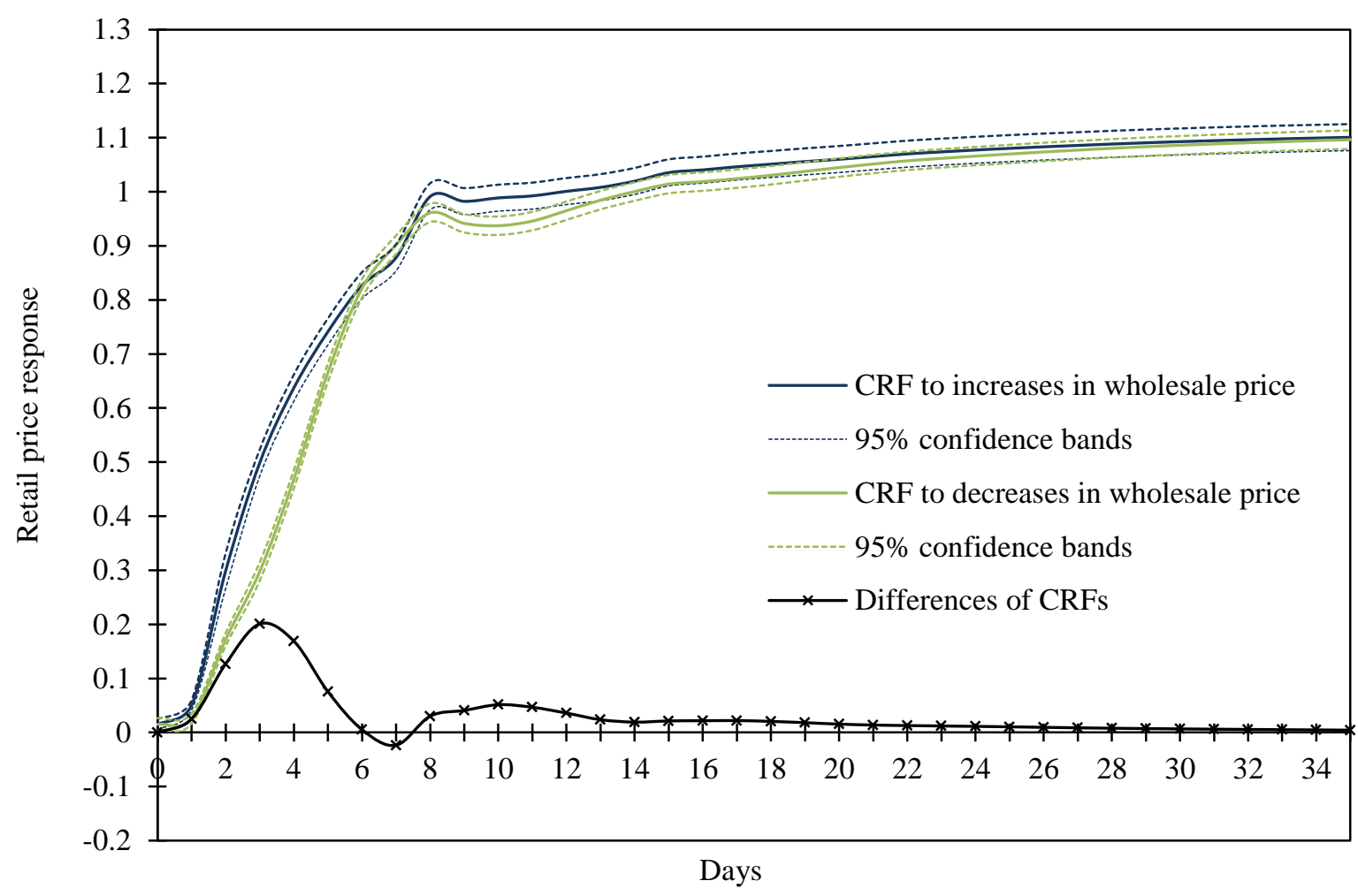

